\title{
Involuntary detained patients' views about risk on admission to hospital Suzanne Curtis
}

\author{
Address: University of Liverpool Department of Psychiatry, Royal Liverpool University Hospital, Liverpool, L69 3GA, UK \\ from WPA Thematic Conference. Coercive Treatment in Psychiatry: A Comprehensive Review \\ Dresden, Germany. 6-8 June 2007 \\ Published: 19 December 2007 \\ BMC Psychiatry 2007, 7(Suppl I):S79 doi:10.1 I86/I47I-244X-7-SI-S79
}

This abstract is available from: http://www.biomedcentral.com/I47I-244X/7/SI/S79

(C) 2007 Curtis; licensee BioMed Central Ltd.

\section{Background}

Evidence suggests that patients who are involuntarily detained because of risk to themselves or others may not recognise after discharge either that they posed a risk or that they suffered from mental disorder [1]. Ward staff may avoid discussing risk with patients who may disagree with their own perceptions of risk [2]. However, discharge planning requires patient and ward nurse to share a common understanding about risk to prevent a recurrence of high risk in that patient in the first few months after discharge from hospital.

\section{Methods}

The multi-center InvolvE study incorporated a pair of questions asking individuals who had been involuntarily detained under the Mental Health Act whether they believed that they were a risk to themselves or others at the time of admission. These questions were repeated up to four times over a one-year period, in order to observe any apparent changes in perception and to link these to some of the other changes taking place over the same time period, such as improvements in mental health, opinions on the justification of involuntary admission and treatment and views on mental illness. In a separate but related qualitative study carried out by the University of Liverpool Department of Psychiatry, involuntarily detained patients and their ward nurses were interviewed at various timepoints on the subject of the risk that the patient presented on admission, how this issue was discussed between nurses and patients and how both parties viewed the relationship between mental illness and risk, especially with reference to assessing readiness for successful discharge into the community.

\section{Results}

This presentation will link the findings of this latter study to an analysis of the InvolvE study's data on risk and consider whether there is any evidence that the treatment patients receive while involuntarily hospitalized brings about a shift in the detained individual's perceptions about risk, thus preparing them for a successful discharge.

\section{References}

I. Gardner W, Lidz CW, Hoge SK, Monahan J, Eisenberg MM, Bennett NS, Mulvey EP, Roth LH: Patients' revisions of their beliefs about the need for hospitalization. Am J Psychiatry 1999, 156: | 385- I39|.

2. Langan J, Lindow V: Living with Risk: Mental Health Service User Involvement in Risk Assessment and Management London: The Foundation for Policy Press; 2004. 